Article

\title{
The Importance of Specific Recycling Information in Designing a Waste Management Scheme
}

\author{
Adekunle Oke ${ }^{1, *}$ and Joanneke Kruijsen ${ }^{2}$ \\ 1 Aberdeen Business School, Robert Gordon University, Aberdeen AB10 1RT, UK \\ 2 Energy and Sustainability, Robert Gordon University, Aberdeen AB10 GJ, UK; J.Kruijsen@rgu.ac.uk \\ * Correspondence: a.o.oke@rgu.ac.uk; Tel.: +44-1224-262000-5010
}

Academic Editor: Michele Rosano

Received: 12 August 2016; Accepted: 2 September 2016; Published: 7 September 2016

\begin{abstract}
Recycling information can be complex and often confusing which may subsequently reduce the participations in any waste recycling schemes. As a result, this research explored the roles as well as the importance of a holistic approach in designing recycling information using 15 expert-based (in-depth) interviews. The rationale was to offer a better understanding of what constitutes waste, recycling, and how recycling information should be designed and presented to make recycling more attractive/convenient. Based on the research participants' perceptions with supports from the existing studies, this research sub-categorised recycling information into three different themes, termed the "WWW" (what, when, and where) of recycling information components. As a result, these components (or attributes) were extensively described (using findings of semi-structured interviews) to elicit pragmatic guidance for practitioners, policy-makers, and other stakeholders in designing structured communication or information strategies that may simplify and subsequently increase waste recycling practices. The policy implications of holistic information in enhancing recycling are further discussed.
\end{abstract}

Keywords: attitudes; behaviour; communication; information; prompts; policy; recycling; waste

\section{Introduction}

The depletion of natural resources, and its associated waste production, has been linked to unsustainable human attitudes and behaviours [1,2]. Nevertheless, an understanding of the thought processes and activities behind the generation of waste may offer new perspectives on how to encourage waste prevention, including resource conservation efforts, without a dramatic change to human behaviours and lifestyles. Waste production is a complex issue [3] confronting local, national, and international governments [4]. Its management may require the integration of inter-disciplinary worldviews while its understanding may be further enhanced using various socio-cultural perspectives [3]. As a result, numerous studies (such as [4,5]) have been conducted within the realms of waste management, many of which focused on socio-demographic and psychological aspects of waste production and management. Findings from these studies have inspired different environmental policies, including legal frameworks that instigated the design of many waste management strategies around the world. Nevertheless, a survey of 2000 households in England suggests that a considerable amount of people (about $30 \%$ of the survey participants) are still confused about what and where to recycle [6].

Policy makers and other stakeholders are therefore confronted with the task of appealing to the subjective and cautious reasoning of individuals in order to instill a waste prevention, reuse, recycling, and/or upcycling ethos. In practice, one of the challenges confronting waste management policy makers and planners is to establish whether recycling information would achieve its intended 
objectives. Another challenge includes the extent (in terms of format, structure, and frequency) at which recycling information should be provided in order to influence behaviours.

As a result, this research was designed to provide a pragmatic guidance for the design of a well-informed communication strategy by exploring the roles and importance of recycling information in modifying recycling behaviour using people's perceptive. On the one hand, the intention was to contribute to the existing knowledge on the effects of information on recycling behaviours and to make recycling more accessible and convenient for people to perform. On the other hand, the research was to encourage a more pro-environmental consciousness and deliberate decision making [2,7] that could impact on the existing consumers' culture and its associated throw-away attitudes.

\section{Information and Recycling Behaviour}

Although the efficacy of using the "individual" as a unit of analysis have been recently challenged [8], the decisions to participate in recycling scheme irrespective of the contexts still rest on the "individual". As a result, the "individual" has a liberty of invoking their subjective judgement when to (or when not to) perform pro-environmental behaviours based on different factors underpinning such a decision-making process. In this respect, different factors such as demographics [9,10]; socio-economics [11,12]; scheme design [4,13]; and identity [14] that are likely to influence recycling behaviour were previously identified. While these factors were well articulated in the literature on recycling at home, factors influencing recycling at work (as well as other contexts) are still sketchy (see [1] for a review). However, the importance of information on recycling schemes in encouraging public involvement have been documented (see $[15,16]$ for a review) albeit no guidance on the components as well as how to design a communication strategy. For example, [17] observed that adequate knowledge of what to recycle through recycling information and provision of feedback were positively significant to recycling behaviour at home. In a similar study, [18] reported a positive influence of publicity and promotion on household recycling behaviour while $[10,19]$ also observed a positive association between recycling knowledge and household waste recycling behaviour. This suggests that recycling information in terms of feedback, publicity, promotion, or a well-designed communication strategy is an effective tool to engage and to enhance recycling behaviour at home [16].

However, behaviour has been reported [19] to return back to the baseline soon after the intervention was withdrawn, suggesting inconsistencies in behaviour over a prolonged period of time. While factors influencing recycling at home are well established and documented, little is known about factors that may likely promote recycling at work (see $[1,20]$ for a review). Nonetheless, the influence of information on recycling at work has been previously investigated (see $[15,21-23]$ for a review). Findings from these studies suggest that information has profound effects on how recycling is practiced at work. Information on recycling schemes can therefore serve as a motivation as well as a barrier to recycling, not only at work but also at home.

Whilst research has attempted to attribute recycling performance to available information on recycling, no known research has established how and in what format including the frequency at which this recycling information should be presented. Consequently, specific information on what (recyclables and non-recyclables), where (location of recycling containers), and how to recycle would enhance recycling behaviour $[15,23,24]$. Although the influence of information is mixed and observed to be behaviour specific [25], it may probably differentiate perceived recyclers from non-recyclers [13]. Further, the importance of a well-designed information to recycling participation is often over-looked and our present knowledge on how recycling information should be designed and presented is still lacking. This includes relevant and important information about the recycling process, recycling scheme, and available recycling facilities that may likely encourage recycling. As a result, the understanding of activities that generate waste (through a holistic information on the dynamics of waste, from production to consumption of materials) is required. This research was designed not only to enhance scheme design but also to promote recycling behaviour. 


\section{Research Methodology}

\subsection{Data Collection}

Recall that the main purpose of this research was to design a "grounded model" of information and/or communication aiming at improving recycling practices by exploring the self-expressing views and perceptions of the participants. However, this current study formed a part of the larger and ongoing study on waste recycling at home and at work in the UK. Using a pragmatist perspective [26-28], the research addressed people's lived experiences and practices in relation to waste recycling in general and assisted in conveying the meanings of waste and recycling. Previous studies on recycling have focused on two major strands representing recycling practices at home and recycling at work. While it is tempting or appropriate to contextualise this research, it is of no practical use to disenfranchise one particular context. As a result, this research addressed the development of information/communication strategies that can be practically adaptable to recycling schemes in any contexts.

In order to understand people's perceptions on the influence of information on their recycling behaviour, qualitative research approach was adopted in this research. Although this study reported on the qualitative interviews, two different perhaps complementary approaches were adopted for data collection: interviews and visual (site) observation. The rationale was to understand the contributions of information to recycling practices using the research participants' worldviews [26]. The first approach involves an in-depth (expert-based) inductive exploration of the participants' subjective views so as to understand how information could be designed and framed [27] within the domain of waste recycling. For this research, experts are not people who only work within waste management sector but also include those who could provide required information in terms of recycling practices at home and at work. This involved gathering specific data relevant to recycling activities and logically making sense of the data using the participants' lived experiences without any theoretical lens. The second approach was conducted to confirm the contributions of existing recycling facilities (such as bin locations and signage/prompts) in the visited sites.

The participants that could provide appropriate data to achieve the research goal were purposefully selected and contacted from different organisations in the UK. A total of 15 semi-structured face-to-face interviews were conducted in person and guided by the interview protocol that was designed for the interview purpose. Rather than the sample size, the richness as well as the appropriateness of the collected data [29] was the central focus of this research. According to Miles and Huberman [30], sample size in explorative, qualitative studies evolves during data collection processes and is not predetermined. Although there is a lack of agreement on the appropriate sample size for qualitative studies [31], the concept of saturation [32] has been adopted in qualitative studies [33]. The sample size as used in this research was sufficient considering that multiple data collection methods were adopted [34]. In addition, about 10 interviews were recommended by Creswell [35] for phenomenology study while 12 participants were considered to be adequate for interview-based study [36]. As a result, the average time for the one-on-one interview was 45 minutes and covered different aspects of waste management and particularly recycling at home and at work. The intention was to understand recycling behaviour (in terms of the motivations and barriers) as well as the participants' views on waste management practices in the UK. Each interview session was digitally recorded following the participants' active consent, transcribed using NVivo 11, and inductively analysed by identifying key themes in terms of recycling information/communication using inductive thematic analysis. In addition, the participants were ascribed with different pseudonyms after been assured of anonymity and confidentiality in line with research ethics and data protection procedure.

The second data collection approach involves visual inspection (or observation) of the existing recycling facilities and to assess the effectiveness of the schemes available in the visited organisations. Using this approach, seven different organisations and two private residential flats where selected 
interviewees work and reside respectively were visited for visual observations. While the interviews were used to espouse the research participants' perception on recycling information, the site observation was undertaken to complement the participants' subjective views and to understand the existing facilities including how recycling is structured within the visited sites. The two approaches were initiated and implemented concurrently between September 2015 and March 2016.

\subsection{Data Analysis}

As previously mentioned, the collected data were inductively analysed without pre-defined themes in order to convey the meanings of the participants' views in a logical and coherent format. Although no distinct themes were generated prior to data collection and analysis, findings from existing studies on recycling behaviour including the researcher's epistemological perspective may bias the identification of themes. In order to identify the emerging themes from the data, the interview transcripts were read through many times for a better understanding of the data and familiarisation.

As a result, thematic analysis [26,37], was performed using NVivo 11-a qualitative data analysis software package. In this approach, the transcripts' contents were categorised and labels were assigned to the emerging themes (categories). For ease of data analysis and synthesis however, the data analytical procedure was informed by Ritchie et al.'s [37] recommendations which included data management (for example data preparation, data labelling, and data itemizing/sorting), abstraction, and interpretation.

\section{Result and Discussion}

\subsection{Participants' Characteristics}

Table 1 shows the socio-demographics of the participants (gender, age, education, employment status, income, and ethnic background).

Table 1. Participants' Socio-demographic Information.

\begin{tabular}{|c|c|c|c|c|c|c|}
\hline Participants & Gender & Age & Education & Employment Status & Income $(£)$ & Ethnic Background \\
\hline 001 & Male & $56-65$ & HNC & Full-time & $25,000-49,999$ & Scottish \\
\hline 002 & Male & $36-45$ & Higher Education & Full-time & $50,000-99,999$ & British \\
\hline 003 & Male & $46-55$ & $\mathrm{~A} / \mathrm{AS}$ & Full-time & $50,000-99,999$ & British \\
\hline 004 & Female & $26-35$ & Higher Education & Full-time & $25,000-49,999$ & British \\
\hline 005 & Male & $46-55$ & Higher Education & Full-time & $50,000-99,999$ & British \\
\hline 006 & Male & $46-55$ & Diploma & Full-time & $>100,000$ & Scottish \\
\hline 007 & Male & $>65$ & Other & Part-time & $<24,999$ & Scottish \\
\hline 008 & Female & $16-25$ & $\begin{array}{l}\text { A/AS/higher } \\
\text { or equivalent }\end{array}$ & Part-time & $<24,999$ & Asian \\
\hline 009 & Female & $26-35$ & Higher Education & Full-time & $<24,999$ & Scottish \\
\hline 010 & Male & $36-45$ & GSCE or Equivalent & Full-time & $25,000-49,999$ & Scottish \\
\hline 011 & Female & $26-35$ & Higher Education & Part-time & $<24,999$ & $\begin{array}{c}\text { Any other } \\
\text { background }\end{array}$ \\
\hline 012 & Male & $56-65$ & $\begin{array}{l}\text { A/AS/higher } \\
\text { or equivalent }\end{array}$ & Full-time & $25,000-49,999$ & Scottish \\
\hline 013 & Male & $36-45$ & Higher Education & Full-time & $25,000-49,999$ & African \\
\hline 014 & Male & $46-55$ & Higher Education & Full-time & $25,000-49,999$ & British \\
\hline 015 & Male & $26-35$ & GSCE or Equivalent & Full-time & $25,000-49,999$ & Scottish \\
\hline \multicolumn{7}{|c|}{ Source: Author } \\
\hline
\end{tabular}

The gender of the participants showed that 4 females and 11 males participated in the study, the youngest participant was between 16 and 25 while the oldest participant was over 65 . Although there was a huge gender difference and skewed toward male participants, the gender difference was not pre-determined and was based on those who responded to the invitation to participate in the research. Considering that e-mail was sent out to invite participants, the gender differences supported the early studies (such as $[38,39]$ ) that observed that males (men) were more likely to respond and participate in a web-based survey compared to their females (women) counterparts. On the other 
hand, it may reflect the dynamics of waste recycling [40] in a household, given that all the participants claimed to be responsible (in charge of) for recycling at home. As a result, it was contrary to [40] who reported that females were more likely to initiate and sustain recycling at home.

Nevertheless, all the participants had one formal education or the other while the highest qualification was a higher degree (Bachelor and above). Although the level of education has no influence on the participants' income (as reflected in Table 1), there is only one extreme case of income at above $£ 100,000$. In addition, the participants included one African, one Asian, while others were White (British and Scottish); this was based on the availability (and accessibility) of the participants rather than the racial landscape of the study context.

\subsection{Recycling Information Components}

Based on the participants' accounts, information aiming at enhancing recycling was broadly categorised into three different themes (see Figure 1). The model (themes) in Figure 1 included what, when, and where (including how) to recycle although the contexts of waste generation were not considered for this analysis. It was assumed in this study that a provision of adequate and correct information is necessary in enhancing recycling irrespective of the waste generation contexts.

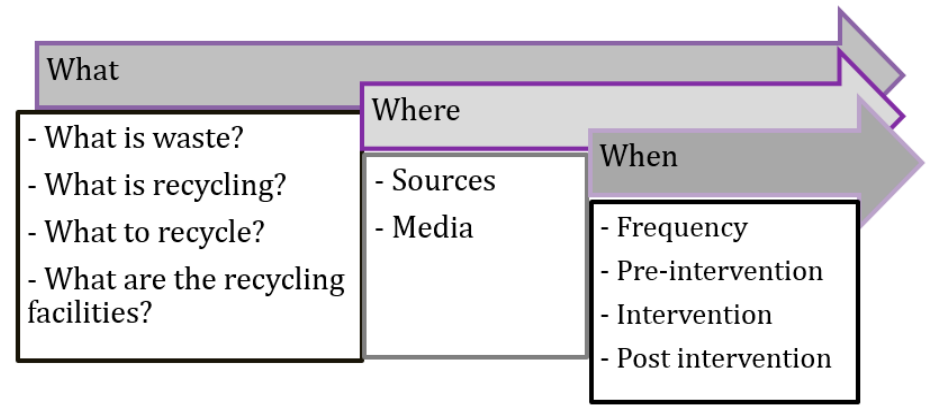

Figure 1. Components of Recycling Information (Source: Author).

As a result, an understanding of these components would not only assist waste planners to design attractive schemes but would also provide an opportunity for people to engage and participate. Rather than focusing on attitude and other socio-psychological attributes of social actors, a well-designed scheme with sufficient information in terms of these components may activate other intrinsic attributes as well as enhancing recycling participation.

\subsection{1. "What" of Waste Recycling}

The "what" of waste-recycling information (see Figure 1 above) as briefly described, analysed, and presented in this study includes: What is waste? What is recycling? What to recycle? What are the recycling facilities?

Waste: What Does It Mean?

Over the years, waste has been construed as the by-product of human activities, particularly resource-intensive and consumer-based economic lifestyles [41], and often disposed of in landfills. This has led to a misconception that waste constitutes materials with no socio-economic and environmental values. This misconception is partially responsible for how waste has been handled and discarded in the past without due consideration of its socio-economic, health, and environmental impacts. However, the perceived scarcity of resources, coupled with the exponential increase in the global population, has changed our impression of what actually constitutes waste. This is based on the mind-set that what constitutes waste in a certain area may constitute a valuable resource (for instance feedstock) in another economic context. As a result, the landscape of waste and waste industry are changing: 
"It's just looking at waste more as resource now rather than just say you pick it up chuck it on the ground; I mean that is industry now we try to move away from calling it waste. Now we see ourselves as resource industry rather than waste industry. So actually what we are trying to do to keep these materials in economy useful as long as possible" (Par_015).

In other words, waste is no longer waste, but is now being regarded as a resource that could find its way back into production lines or manufacturing processes:

"One of the key achievements is something like reduction in disposal of biodegradable waste by given alternatives to other technologies like composting, AD stops co-disposal of solid and liquid waste going into the landfill thereby activation some other waste streams like spread the waste on land as fertiliser. So it has activated that particular industry, so that industry has employed so many people in terms of land spreading of waste on agricultural land which is one of the recovery avenues" (Par_013).

Considering the global amount of waste generation at 1.3 billion tonnes per year [41], this may be catastrophic if people still perceive this valuable resource as waste. Rather than for people to throw away what they buy [4] or not have the habit of recycling [5], people should be aware that the throw away culture is a thing of the past.

"People know now that they can't just throw your rubbish away, stuff got to be recycled whenever possible" (Par_006).

As a result, there should be more clarification on the materials that are recyclable and schemes should be designed to facilitate the collection of these materials in order to enhance the global circular economy initiatives. This could provide an opportunity to develop structured and unstructured markets for materials that are perceived to be waste, including items being produced from recycled materials. When designing recycling information therefore, there should be more clarity about items that could be recycled. As a result, a sufficient knowledge of materials that can be recycled (and/or sold) would not only influence the subjective reasoning of consumers but could also reinforce the actions of conscious (ethical) consumers.

How Should We Frame Recycling?

Recycling which is the preferred "waste treatment" method based on the tenets of waste hierarchy has been reported (such as [42]) as a gateway to other pro-environmental behaviours. In other words, a social agent that develops a habit of recycling is more likely to adopt other pro-environmental behaviours such as energy conservation. What constitutes recycling is well defined in policy statements (such as [43]). However, many people are confused about the whole idea of recycling and may likely affect how they recycle:

"In the UK you'll find that a lot of people still don't recycle although nowadays you've got street bins that household waste to go in, is still to getting people to realise we've got to recycle, that will be hardest" (Par_001).

Whereas the definition of recycling practically clarifies what is and what is not a recycling activity, it suggests that recycling is beyond the capacity of consumers. For example:

"I think recycling can be considered as just throwing away your trash, throwing away any thrash recycling is now I think considered as splitting up the type of trash" (Par_008).

In this study therefore, recycling is conceived as a material reprocessing (through "production/manufacturing") involving physical, chemical, mechanical, and thermal processes to derive initial or other products. As a result, labelling or profiling consumers as recyclers or non-recyclers (such as $[13,44]$ ) is taxonomically misleading and could undermine the important roles 
of consumers in the waste-recycling cycle. Recycling information may therefore be ill-defined and not properly structured in a way that could influence behaviour. The major challenge is to identify what constitutes the roles of individuals (consumers) along the chain of recycling in order to focus recycling information on those specific roles and responsibilities. Considering that "there is a growing emphasis on recycling now and recovery of waste" (Par_013); technically, the responsibility of individuals within the cycle is limited to the preparation (such as sorting, washing, drying, and possibly transportation) of materials for recycling.

From these perspectives, it is conceivable to suggest that the waste-recycling process should not be represented as a single activity but as multiple activities, with each preceding activity leading to the next activity in a cycle. As a result, waste recycling can be conceived as a technical process that is more than tossing a used material or an item into a designated bin in terms of the available collection scheme-commingle or source separation. In other words, commingling and/or source separation of waste are not recycling in their own rights, rather they are methods involved in preparing materials (waste) for collection. Recycling requires more efforts where putting (un)used items into collection bins (either through commingle or source separation) is only a first stage of recycling cycle while the responsibility of individuals (or consumers) should be termed "preparing for recycling" instead of recycling itself.

\section{What (Materials) Should We "Prepare" for Recycling?}

This aspect of waste-recycling information differentiates what to prepare for recycling from what is to dispose through incineration and/or landfills. In other words, it explains the materials that can be deposited in dedicated recycling bins and those that are going into trash/disposal bins. According to the research participants:

"I feel maybe people don't know what materials they can recycle, so there's a bit of confusion about can you recycle this, can you recycle that" (Par_008).

The understanding of these materials will facilitate ease of recycling and also enhance the quality of materials being collected for recycling. This might differ from one location to another based on local facilities and capacities to handle (or process) the available materials:

"There is always a different system and different councils have different steps as well-some collect glass, some have to separate glass and some the collections (times) are different as well; some you've to walk around the corner to put your materials right there" (Par_002).

What constitutes recyclables may also be influenced by the legal and economic requirements of a particular country or region. In the UK for example:

"The main piece of legislation is Environmental Protection Act 1990 that put in place something like recycling targets, local authority recycling plans, it made landfill more regulated and try to bring in landfill tax. That was a big drive in terms of the change in industry" (Par_015).

Nevertheless, different materials are produced and prepared for recycling by the participants:

"Paper, cardboard, cereal boxes, newspapers, magazines-we don't have many magazines, but tins, cans, aerosols, foil trays and what else yeah plastic bottles and glass we get" (Par_004).

This was supported by Austin et al. [21] who identified plastics, metals, glass, paper, wood, and bio-waste (mainly organic waste in nature) as major recyclables. In order to reduce any misconception about the materials that can be recycled, the key recyclables are identified in the EU Waste Framework Directive (2008/98/EC) for instance. While paper (including newspapers and magazines) was reported by all the participants, clothes were the least mentioned materials. This was supported by Barr [4] and Perrin and Barton [17] who observed that paper was the most recycled material while textile was 
the least recycled material by householders in the UK. The identification of these materials as major recyclables is primarily influenced by their economic, social, and environmental importance.

The provision of adequate information about these materials is necessary to create an informed awareness so as to facilitate ease of recycling and to ensure that "preparing for recycling" is convenient for people to undertake. This is based on the available evidence (such as $[15,16,21]$ ) of a strong relationship between specific information concerning the key recyclables and waste-recycling behaviour. However, the contribution of environmental knowledge in enhancing pro-environmental behaviours is still contentious and findings on the effect of environmental knowledge are mixed in the literature. For example, while [45] observed positive effects of environmental knowledge, [46] concluded that environmental knowledge has little or no effects on behaviours. Nevertheless, studies (such as $[14,17,47]$ ) have shown that sufficient knowledge of materials that can be recycled enhances recycling behaviour. It is intuitive to conclude that the provision of specific information on what to recycle could increase recycling awareness and subsequently influence recycling behaviour. On the contrary, provision of information alone may not be sufficient in its own right to influence recycling participation $[17,48]$. Accordingly, the relevance of recycling information may be discounted by the introduction of policy-based instruments [13] or market-based instruments [17] that may facilitate ease of recycling. On the other hand, the contents, including the medium, of disseminating recycling information are both important in enhancing recycling behaviour [48].

Although the provision of recycling information alone may not be sufficient in enhancing recycling behaviour [17], the absence of specific information could serve as a barrier to waste-recycling behaviour [1,49]. Recycling information, when available, may practically differentiate perceived recyclers from non-recyclers $[44,50]$ and this may inform policy or strategy that enhances recycling. For instance:

"Even though bins are provided it helps to put up the sign and specify what one goes into which kind of thing" (Par_006).

As a result, provision of sufficient information on recyclables is likely to influence recycling behaviour and also the quality of materials for recycling.

What Facilities Are Available for Recycling?

Having provided information on what constitutes waste, including materials that can be collected for recycling, there is a necessity to provide adequate information about where the materials can be deposited for the purpose of recycling. Accessibility to appropriate recycling facilities is a crucial factor in enhancing recycling participation and serves as one of the success criteria for any recycling scheme. According to the participants' accounts for instance:

"If it (the facility) is easily accessible, it's feasible then I think a lot of more people will recycle" (Par_011).

This may either facilitate the ease of recycling when accessible or makes recycling more challenging to perform when not accessible:

"At home at the moment we have general waste bin, we've got food waste as well that's on street service and the recycling I'll go around to (a supermarket's name) just down there and recycle glass, paper, cardboard, tins, cans, plastic bottle and I've also got a drink cutting recycling bin for tetra packs" (Par_004).

Accordingly, access to facilities and recycling behaviour are observed to be positively correlated [4,10,19,47].

In addition, the place of residence as well as the type of accommodation and the nature of community can influence the provision and accessibility of appropriate recycling facilities:

"A lot of recycling is down to the area where you live" (Par_006). 
"I think it's very much depends on the area you live in whether you recycle or not, whether you're wealthy or you live in a sort of less wealthy area" (Par_008).

"We stay in apartment at home which is got communal bins, we recycle as best as we can, papers are; we collect papers and put them in the recycling bins, everything else no I don't recycle at all" (Par_001).

These may be associated with economies of scale on the part of government and convenience on the part of resident:

"Where I live on my street, there aren't really any recycling bins either, we have one black general waste bin and is collected every second Tuesday; and many of my neighbours put their recycling in that bin and they all have cars however they don't drive down which is five minutes-drive down to a sort of recycling centre" (Par_011).

For example, rural dwellers may not produce enough waste to attract investments in recycling facilities and may result in a lack of appropriate facilities:

"If there's not enough containers to service an area you going to have a problem. I think that's where the real cost is-is the infrastructure on the ground where are not seeing a right investment or investment in right places both in real process and capabilities" (Par_002).

Whereas people, especially those in multi-family apartment, may consider recycling to be inconvenient due to a lack of storage space:

"We just don't have the bins, we don't have storage facilities; if we do have glass bottles or plastic bottles we don't have that facilities to store them, you know flats are like that, you don't space for storage so you just have to put them in the general bin" (Par_001).

Although the available options may be different in rural areas compared to urban (and suburban) communities, recycling facilities can range from simple caddies, desk bins, and outdoor kerbside containers to various recycling centers or drop-off points. Many of these dedicated sites, including supermarkets and other places (such as Household Waste Recycling Centers), have provisions for containers where specific materials can be deposited for recycling. For instance:

"So what I do is that we have a balcony so anything we need to recycle we actually put on the balcony and then when we decide to make a trip to either (supermarket's names) we take the recycling and put in the recycling centre" (Par_011).

In the UK, for example, besides some designated recycling locations (and drop-off points), the household waste recycling centers (HWRCs) previously known as Civic Amenity sites allow householders to transport their bulky materials for recycling. It is worth noting that HWRCs only receive bulky (household items) materials such as mattresses and furniture from householders. The intention of these drop-off points is to make recycling facilities available and as accessible as possible for residents and also to prevent fly tipping or open dumping. Nonetheless, a lack of adequate facilities was observed [51,52] as one of the barriers for participating in recycling schemes. If recycling facilities are really important in waste collection for recycling, then how adequate and convenient are these facilities for their users? What sort of information, and in what format, is available to the public about their usage? These are pertinent questions that should be addressed in order to make recycling facilities accessible. Inability to address these questions may reduce the likelihood of recycling participation and render these facilities inadequate when preparing materials for recycling. For example, [50] observed that recycling logistics have a positive influence on recycling behaviours while [13] reported that the appearance and size of recycling bins are some of the barriers to community waste recycling. While the existence of sufficient facilities enhances recycling behaviour [53] information about the facilities [10] could make the facilities more accessible. As a result, a well-designed scheme with provision of structured recycling information is more effective compared to provision of monetary incentives [54]. 


\subsection{2. "Where" of Waste Recycling Information}

The discussion has focused on the "what" of recycling information, this section therefore focused on the "where" of recycling information in terms of its sources and/or medium dissemination. For instance, one of the interviewees reckoned that:

"It has become more apparently feasible in the media in recent years" (Par_011).

Different sources of recycling information are identified in the literature on recycling behaviour (such as $[10,16]$ ). These sources included print (such as leaflets, local newspapers, government environmental newspapers, and posters) and broadcast or online media (for instance radio, television and the internet, including social media and intranet). For instance:

"I guess it kind of ties with the council given you specific bins to do this and I think you start to think more about it. And everywhere you look through the papers, media there's always about do you do your bit for the environment be it recycling, do you turn the lights off and that kind of stuff? So I think the advertising campaigns are effective" (Par_005).

In addition, anecdotal evidence suggests that personal contact and public consultation have been well adopted by some local councils, especially in the UK. Accordingly, access to recycling information and how that information is structured not only has a significant influence on waste-recycling behaviour but is also observed to mediate the influence of other factors [18,55].

The importance of recycling information sources cannot be underestimated as this may determine the degree of acceptance as well as participation in waste-recycling schemes. The credibility and reliability of recycling information may be influenced by the sources, which could consequently affect peoples' behaviour and participation in recycling schemes. For example, local council environmental newspapers [12] and leaflets [16] were observed to be more effective in influencing recycling behaviour compared to local newspapers. For example:

"I think publicity, social media—all these kind of things—are far more prominent and has been for the last 10 years or something like that. The awareness comes from social media, council publications I guess they influence us" (Par_005).

Compared to local or marketing newspapers, local councils' environmental newspapers or leaflets contain specific recycling information and feedback such as recycling performances, recycling targets, location of the local recycling facilities and description of recyclables that local newspapers would not necessarily report. In other words, local councils' communication strategies contain both declarative and procedural information that influence waste recycling participation as well as behaviour. In addition, [47] observed that door-stepping techniques (personal contact) are more effective in encouraging as well as increasing recycling rates. The views of the research participants were in support of these techniques in enhancing recycling:

"Obviously, the recycling office is going to visit schools and especially the primary kids, you get them involved, you get them enthusiastic and you know they will say oh the kids will go home and tell the parents what to do and what not to do and things" (Par_004).

"The kids are getting education at school, learning about recycling. They come to me then sometimes and ask me questions about can this go, which bin does this go" (Par_002).

Apart from creating awareness about the on-going schemes in any locality, an education campaign may also improve existing knowledge of what, where, and how to recycle. This was corroborated by Nixon and Saphores [12] who observed a relationship between publicity (and promotion) and recycling behaviour. This suggests that recycling publicity and promotion or a well-designed communication strategy can be an effective tool to engage or enhance recycling behaviour [16]. However, the rate of household waste recycling was observed to reduce soon after the campaign ended, which shows that the recycling behaviour could not be sustained beyond the period of information [52]. One possible 
reason for this could be that recycling barriers and/or other situational factors were not identified and addressed [1] prior to and during the campaign. Some of these barriers may include lack of facilities, proximity of the facilities, and recycling scheme design. In addition, recycling promotion or publicity adverts should be regularly updated in order to be more effective and engaging with respect to current waste-recycling issues. Multiple sources of recycling information may be considered when disseminating recycling information; this may be more helpful in increasing recycling knowledge than a single source of information [44]. However, recycling information through a reliable or credible channel with a certain degree of authority such as local councils may enhance and sustain recycling behaviour. As a result, multiple sources of recycling information may be considered when disseminating recycling information; this may be more reliable for the increase of recycling knowledge than a single source of information [12]. While an information campaign is important to enhance waste recycling, its relevance could diminish by the introduction of policy instruments and other external factors that may enhance simplicity of recycling [13,49].

\subsection{3. "When" of Recycling Information}

Recycling information may not be effective without a clear understanding of the stage at which the information should be provided. Previous projects have adopted and introduced specific recycling information, in particular prompts before and after the introduction of recycling schemes. While information was used prior to the scheme to create scheme awareness [10,56], performance feedback [47] was used after the scheme implementation. In addition, performance feedback has been reported to enhance the quality of materials for recycling by reducing the amount of contaminants [48]. Prior intervention information and performance feedback may therefore serve as motivations or incentives for participation in the scheme. Nonetheless, the provision of feedback on recycling performance was observed to be less effective compared to financial or monetary incentives [48]. Although feedback may be less effective compared to other incentives, recycling behaviour is significantly influenced by prior-scheme information and performance feedback [16,47]. While the effects of the timing of the introduction of recycling information are still ambiguous, there is a likelihood that prior-scheme recycling information would be more effective, especially in recruiting new participants. For instance:

"When that blue bin turned up with the green waste caddy, I don't know anything about that as a householder; no leaflets through your door, no information about it; pull out the green caddy bin what the hell is this for, do I put my bag in that, there's a little mesh thing sitting where does this go? Does it go in my utility room, do I fill what? I don't even know how to use the system so the education we got from that was slightly that lustre, I think that's the key thing as well as you know you got to get that education before you rolling out make sure everybody is aware of what they are going to do and then sustain it as well" (Par_002).

On the other hand, recycling information being provided (in terms of performance feedback) after introducing the scheme could be more effective in enhancing participation rates. In other words, performance feedback could be adopted to encourage those who are already participating in the recycling scheme. As a result, the stage at which recycling information is introduced will influence the nature of information and could also affect how people engage and participate in the scheme. For example, provision of waste-recycling information prior to a recycling scheme may offer sufficient time for people to reflect on it so as to clearly understand the scheme, including their participation. This may enhance the participants' knowledge of different facilities, including the scheme's requirements relating to frequency of collection and materials to be collected for recycling. Like any other interventions, the target behaviour may return to the baseline when the information or prompts are discontinued. The reliability and effectiveness of recycling information (or prompts) may therefore diminish over a long period of time [25]. The major challenge is how to sustain the effectiveness of this aspect of recycling information without diminishing the values of the recycling scheme. One possibility is to continuously update the recycling information at regular intervals when 
the performance (in terms of the quantity and quality of materials being collected for recycling) is observed to be deteriorating. This means there needs to be a system for the continuous monitoring and improvement of the scheme throughout its entire lifecycle. This is necessary due to the fact that waste management (recycling) requirements are dynamic based on the increasing changes in waste management legislation and/or regulation including the complexity of human behaviours.

In this study, therefore, it is suggested that coherent waste recycling information that explains the where, what, and when (and how) of waste recycling should be made available at least three months prior to the introduction of a scheme. Whilst there is no theoretical or philosophical basis for the selection of this time frame, it may be socially and technically desirable to allow sufficient time for behavioural adjustment that could influence people's level of preparedness. If the major reasons for not recycling are inconvenience, distance, and other waste-handling issues [47], giving the participants some valuable information prior to the commencement of a scheme would provide an opportunity to assess their status against the scheme's demands. Participants would also be made aware of the facilities such as recycling centers and types of recycling schemes (such as commingle) existing in their local jurisdiction. For instance, participants may not be conversant with (or aware of) the recycling facilities in their area despite the proximity of such facilities (see $[44,56]$ for a review). From this review, it is argued that adequate and specific recycling information should be provided before the implementation of a particular scheme in order to create scheme awareness. In order to enhance participation, performance feedback should also be provided at regular intervals during and after the scheme introduction in order to sustain the relevance of recycling information.

\section{Conclusion}

In this research, the need for coherent and all-encompassing waste-recycling information was discussed and presented. Using the research participants' views and findings from the literature, we argued that coherent information creates scheme awareness and also provides opportunities for planners to design effective schemes that may be more attractive in encouraging participation. In addition, this study deliberately re-positioned waste recycling responsibilities based on the acceptable and legal definitions of waste and recycling. According to this study, the definition of recycling absolves individuals from any responsibilities of recycling. Instead, preparation of materials for collection was argued in this research to be the major responsibility of individuals or householders. Recycling is more than tossing materials in dedicated bins: it requires additional efforts such as chemical, thermal, or mechanical processes. On this basis, this study presents recycling as a technical activity that could only be performed by specialised waste management (or recycling) firms with appropriate facilities or capacities for recycling. Further, this research extends the on-going discussion on the legality of the existing definition of waste and identifies key recyclables that householders or individuals could prepare for recycling.

In support of these arguments, waste recycling information was sub-classified into three distinct segments-what, where, and when. The rationale was to provide scheme designers, policy-makers, and participants with an opportunity to address and understand how the materials that should be prepared for recycling could be enhanced. While previous studies have identified different factors that may influence recycling behaviours, this paper offered support to studies that have demonstrated that recycling information or communication is an effective strategy in influencing participation. However, the effects of information can be diminished with time and context, there should be more clarification concerning the what, when, and where of waste recycling information. It was argued that policies, strategies, and waste management schemes are more effective when holistic information is incorporated into the scheme design.

However, the description of waste recycling information is not complete without further knowledge about why and how waste recycling should be carried out. The "why" would provide necessary information concerning the reasons or the necessities for recycling while "how" explains the process or the procedure in recycling. As a result, procedural information would facilitate ease of preparing materials for recycling and may influence scheme participations. All these attributes of 
recycling information should be taken into consideration and be applied in tandem when designing or developing waste management strategies or policies that could enhance public involvement. It is therefore anticipated that an understanding of the whole network of recycling process (or interlinks) as discussed in this research would result in the full knowledge of materials that should be prepared for recycling which may consequently enhance recycling practices.

\section{Recommendations}

As a result of these findings, we would like to make the following recommendations especially for policy makers as well as practitioners:

1. Information aiming at enhancing recycling participation should be more explicit in terms of what, when, and where including how to recycle

2. When designing and disseminating recycling information, information recipients should be made aware of the importance of recycling and why they should recycle in the first place. As a result, recycling information should be both prescriptive and procedural in terms of recycling (including the items to recycle) and participation

3. There is a need to constantly updating recycling information so as to keep up with dynamics of people's behaviour in terms of waste generation and also to reflect seasonal patterns considering the effect of time and contexts on recycling information

4. In order to incentivize and to enhance recycling behaviour, there should be a mechanism for feedback on recycling performance

5. The provision of recycling information (and/or communication) should facilitate ease and accessibility of recycling schemes and should target perceived recyclers and non-recyclers.

Acknowledgments: The authors are grateful for the contributions of Seonaidh McDonald (Aberdeen Business School, Robert Gordon University), Sarah Pedersen (Department of Communication, Robert Gordon University), and Evagelos Korobilis-Magas (Marketing Department, Aberdeen Business School, Robert Gordon University). In addition, we express our gratitude to the independent reviewers for their contributions and suggestions. The author(s) received no financial support for the research, authorship, and/or publication of this article.

Author Contributions: Before her death, Joanneke was instrumental to this manuscript and also proofread the initial draft. Adekunle designed and conducted the interviews, transcribed and analysed the data, and wrote the entire paper.

Conflicts of Interest: The authors declare no conflict of interest and no funding was received as part of this research.

\section{References}

1. Oke, A. Workplace waste recycling behaviour: A meta-analytical review. Sustainability 2015, 7, 7175-7194. [CrossRef]

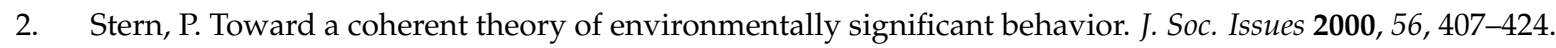
[CrossRef]

3. Ekström, K.M. Waste Management and Sustainable Consumption: Reflections on Consumer Waste; Routledge Taylor and Francis Group: New York, NY, USA, 2015.

4. Barr, S. What we buy, what we throw away and how we use our voice: Sustainable household waste management in the UK. Sustain. Dev. 2004, 12, 32-44. [CrossRef]

5. Knussen, C.; Yule, F. "I'm not in the habit of recycling" The role of habitual behavior in the disposal of household waste. Environ. Behav. 2008, 40, 683-702. [CrossRef]

6. Moore, D. Thirty Percent of Residents "Confused" about What Can Be Recycled. Chartered Institution of Wastes Management Journal, 2015. Available online: http://www.ciwm-journal.co.uk/thirty-percent-ofresidents-confused-about-what-can-be-recycled/ (accessed on 5 July 2015).

7. Kollmuss, A.; Agyeman, J. Mind the gap: Why do people act environmentally and what are the barriers to pro-environmental behavior? Environ. Educ. Res. 2002, 8, 239-260. [CrossRef]

8. McDonald, S.; Oates, C.J.; Alevizou, P.J. No through road: A critical examination of researcher assumptions and approaches to researching sustainability. Rev. Mark. Res. 2016, 13, 139-168. 
9. Garcés, C.; Lafuente, A.; Pedraja, M.; Rivera, P. Urban waste recycling behaviour: Antecedents of participation in a selective collection programme. Environ. Manag. 2002, 30, 378-390. [CrossRef] [PubMed]

10. Vicente, P.; Reis, E. Factors influencing households' participation in recycling. Waste Manag. Res. 2008, 26, 140-146. [CrossRef]

11. Berglund, C. The assessment of households' recycling costs: The role of personal motives. Ecol. Econ. 2006, 56, 560-569. [CrossRef]

12. Nixon, H.; Saphores, J.D.M. Information and the decision to recycle: results from a survey of us households. J. Environ. Plan. Manag. 2009, 52, 257-277. [CrossRef]

13. McDonald, S.; Oates, C. Reasons for Non-Participation in a Kerbside Recycling Scheme. Resour. Conserv. Recycl. 2003, 39, 369-385. [CrossRef]

14. Thøgersen, J. Monetary Incentives and Recycling: Behavioural and psychological reactions to a performance-dependent garbage fee. J. Consum. Policy 2003, 26, 197-228. [CrossRef]

15. Kaplowitz, M.D.; Yeboah, F.K.; Thorp, L.; Wilson, A.M. Garnering input for recycling communication strategies at a big ten university. Resour. Conserv. Recycl. 2009, 53, 612-623. [CrossRef]

16. Mee, N.; Clewes, P.S.; Phillips, P.S.; Read, A.D. Effective implementation of a marketing communications strategy for kerbside recycling: A case study from Rushcliffe (UK). Resour. Conserv. Recycl. 2004, 41, 1-26. [CrossRef]

17. Perrin, D.; Barton, J. Issues associated with transforming household attitudes and opinions into materials recovery: A review of two kerbside recycling schemes. Resour. Conserv. Recycl. 2001, 3, 61-74. [CrossRef]

18. Evison, T.; Read, A.D. Local Authority Recycling and Waste-Awareness Publicity and Promotion. Resour. Conserv. Recycl. 2001, 32, 275-292. [CrossRef]

19. Grodzinska-Jurczak, M.; Tomal, P.; Tarabuła-fiertak, M.; Nieszporek, K.; Read, A.D. Effects of an Educational Campaign on Public Environmental Attitudes and Behaviour in Poland. Resour. Conserv. Recycl. 2005, 46, 182-197. [CrossRef]

20. McDonald, S. Green Behaviour: Differences in Recycling Behaviour between the Home and the Workplace. In Going Green: The Psychology of Sustainability in the Workplace; Bartlett, D., Ed.; The British Psychological Society: Leicester, UK, 2011; pp. 59-64.

21. Austin, J.; Hatfield, D.; Grindie, A.; Bailey, J. Increasing recycling in office environments: The Effects of Specific Informative Cues. J. Appl. Behav. Anal. 1993, 26, 247-253. [CrossRef] [PubMed]

22. Brothers, K.J.; Krantz, P.J.; McClannahan, L.E. Office paper recycling: A function of container proximity. J. Appl. Behav. Anal. 1994, 1, 153-160. [CrossRef]

23. Kelly, T.C.; Mason, I.G.; Leiss, M.W.; Ganesh, S. University community responses to on-campus resource recycling. Resour. Conserv. Recycl. 2006, 47, 42-55. [CrossRef]

24. Humphrey, C.R.; Bord, R.J.; Hammond, M.M.; Mann, S.H. Attitudes and Conditions for Cooperation in a Paper Recycling Program. Environ. Behav. 1977, 9, 107-124. [CrossRef]

25. De Young, R. Changing behavior and making it stick: The conceptualization and management of conservation behavior. Environ. Behav. 1993, 25, 485-505. [CrossRef]

26. Bryman, A. Social Research Methods, 4th ed.; Oxford University Press: Oxford, UK, 2012.

27. Creswell, J.W. A Concise Introduction to Mixed Methods Research; Sage Publications: Thousand Oaks, CA, USA, 2014.

28. Tashakkori, A.; Teddlie, C. (Eds.) Sage Handbook of Mixed Methods in Social E Behavioral Research; Sage Publications: Thousand Oaks, CA, USA, 2010.

29. Bowen, G.A. Naturalistic inquiry and the saturation concept: a research note. Qual. Res. 2008, 1, 137-152. [CrossRef]

30. Miles, M.B.; Huberman, A.M. Qualitative Data Analysis: An Expanded Sourcebook; Sage Publications: Thousand Oaks, CA, USA, 1994.

31. Bryman, A. Social Research Methods, 5th ed.; Oxford University Press: Oxford, UK, 2016.

32. Strauss, A.; Corbin, J. Basics of Qualitative Research: Techniques and Procedures for Developing Grounded Theory; Sage Publications: Thousand Oaks, CA, USA, 1998.

33. Charmaz, K. Constructing Grounded Theory: A Practical Guide through Qualitative Analysis; Sage Publications: Thousand Oaks, CA, USA, 2006.

34. Lee, D.T.F.; Woo, J.; Mackenzie, A.E. The cultural context of adjusting to nursing home life: Chinese elders' perspectives. Gerontologist 2002, 5, 667-675. [CrossRef] 
35. Creswell, J. Qualitative Inquiry and Research Design: Choosing among Five Traditions; Sage Publications: Thousand Oaks, CA, USA, 1998.

36. Guest, G.; Bunce, A.; Johnson, L. How many interviews are enough? An experiment with data saturation and variability. Field Methods 2006, 1, 59-82. [CrossRef]

37. Ritchie, J.; Lewis, J.; Nicholls, C.M.; Ormston, R. (Eds.) Qualitative Research Practice: A Guide for Social Science Students and Researchers; Sage Publications: Thousand Oaks, CA, USA, 2013.

38. Pitkow, J.E.; Kehoe, C.M. Emerging trends in the WWW user population. Commun. ACM 1996, 6, 106-108. [CrossRef]

39. Smith, M.A.; Leigh, B. Virtual subjects: Using the Internet as an alternative source of subjects and research environment. Behav. Res. Methods Instrum. Comput. 1997, 4, 496-505. [CrossRef]

40. Oates, C. J.; McDonald, S. Recycling and the Domestic Division of Labour: Is Green Pink or Blue? Sociology 2006, 40, 417-433. [CrossRef]

41. The World Bank. What a Waste A Global Review of Solid Waste Management. Urban Development Series Knowledge Papers. 2012. Available online: http://www-wds.worldbank.org/external/ default/WDSContentServer/WDSP/IB/2014/09/17/000442464_20140917123945/Rendered/PDF/ 681350REVISED00t0a0Waste020120Final.pdf (accessed on 4 January 2014).

42. Berger, I.E. The demographics of recycling and the structure of environmental behavior. Environ. Behav. 1997, 29, 515-531. [CrossRef]

43. The European Parliament and the Council of the European Union. Directive 2008/98/EC of the European Parliament and of the Council. 2008. Available online: http:/ / eur-lex.europa.eu/LexUriServ/LexUriServ. do?uri=OJ:L:2008:312:0003:0030:EN:PDF (accessed on 22 May 2013).

44. De Young, R. Exploring the difference between recyclers and non-recyclers: The role of information. J. Environ. Syst. 1988, 18, 341-351. [CrossRef]

45. Mainieri, T.; Barnett, E.G.; Valdero, T.R.; Unipan, J.B.; Oskamp, S. Green buying: The influence of environmental concern on consumer behavior. J. Soc. Psychol. 1997, 137, 189-204. [CrossRef]

46. Grob, A. A structural model of environmental attitudes and behaviour. J. Environ. Psychol. 1995, 15, $209-220$. [CrossRef]

47. Timlett, R.E.; Williams, I.D. Public participation and recycling performance in England: A comparison of tools for behaviour change. Resour. Conserv. Recycl. 2008, 52, 622-634. [CrossRef]

48. Chung, S.S.; Poon, C.S. Hong Kong citizens' attitude towards waste recycling and waste minimization measures. Resour. Conserv. Recycl. 1994, 10, 377-400. [CrossRef]

49. Hage, O.; Söderholm, P.; Berglund, C. Norms and Economic Motivation in Household Recycling: Empirical Evidence from Sweden. Resour. Conserv. Recycl. 2008, 53, 155-165. [CrossRef]

50. Ebreo, A.; Vining, J. Motives as predictors of the public's attitudes toward solid waste issues. Environ. Manag. 2000, 25, 153-168. [CrossRef] [PubMed]

51. Barr, S. Factors influencing environmental attitudes and behaviors: A UK case study of household waste management. Environ. Behav. 2007, 39, 435-473. [CrossRef]

52. Knussen, C.; Yule, F.; Mackenzie, J.; Wells, M. An Analysis of Intentions to Recycle Household Waste: The roles of past behaviour, perceived habit, and perceived lack of facilities. J. Environ. Psychol. 2004, 24, 237-246. [CrossRef]

53. Luyben, P.; Cummings, S. Motivating beverage container recycling on a college campus. J. Environ. Syst. 1981, 11, 235-245. [CrossRef]

54. Iyer, E.S.; Kashyap, R.K. Consumer recycling: Role of incentives, information, and social class. J. Consum. Behav. 2007, 6, 32-47. [CrossRef]

55. Kalsher, M.J.; Rodocker, A.J.; Racicot, B.M.; Wogalter, M.S. Promoting Recycling Behavior in Office Environments. In Proceedings of the Human Factors and Ergonomics Society Annual Meeting, Seattle, WA, USA, 11-15 October 1993; SAGE Publications: Thousand Oaks, CA, USA, 1993; pp. 484-488.

56. McDonald, S.; Ball, R. Public Participation in Plastics Recycling Schemes. Resour. Conserv. Recycl. 1998, 22, 123-141. [CrossRef]

(C) 2016 by the authors; licensee MDPI, Basel, Switzerland. This article is an open access article distributed under the terms and conditions of the Creative Commons Attribution (CC-BY) license (http://creativecommons.org/licenses/by/4.0/). 